\title{
Retos para la universidad 2020 en Venezuela
}

\author{
LUIS UGALDE
}

Jesuita. Licenciado en Filosofía y Letras, Teología y Sociología. Magister en Historia y Doctor en Historia. Ha sido rector de la Universidad Católica Andrés Bello por 20 años y Presidente de la Asociación de Universidades de la Compañía de Jesús de América Latina (AUSJAL).

\section{Resumen}

El presente artículo aborda la dramática situación actual de la universidad venezolana y su pérdida extrema de presupuesto, profesores, investigadores, personal y estudiantes; es indispensable recrearla, junto con la recuperación democrática de la nación. Se reconocen y recuerdan los logros y éxitos de la universidad venezolana durante las primeras décadas de la democracia de 1958. La universidad creció vertiginosamente en número, calidad, diversificación y presencia en la geografía nacional. En esos años, se contó con un generoso financiamiento nacional gracias a los crecientes ingresos petroleros, lo que permitió que cientos de miles de familias, que nunca habían llegado a la universidad, celebraran la graduación de sus hijas e hijos. La universidad fue el mejor medio de ascenso social y fuente de profesionales para una sociedad que rápidamente pasaba de lo rural a lo urbano, y para la creciente "industria de la sustitución de importaciones". Todo ello con autonomía universitaria y libertad de cátedra incluso en los momentos del enfrentamiento guerrillero inspirado y apoyado por el régimen cubano. El artículo señala que no es posible reconstruir la universidad venezolana con los esquemas y modelos anteriores debido a que el Estado está endeudado, arruinado, y con la empresa productora en agonía. Renacer requiere una alianza fuerte, efectiva y productiva entre la empresa y la universidad, con la diversificación de las fuentes de auspicio, y el restablecimiento de la autonomía y la libertad de cátedra. Se mencionan a su vez algunas condiciones indispensables para el renacimiento de la universidad.

Palabras clave

Ruina del país y de la universidad. Cambio democrático, renacer y autonomía. 


\title{
Challenges to the university in Venezuela 2020
}

\begin{abstract}
This review presents the current dramatic situation of Venezuelan university: an extreme loss of budget, teachers, researchers, personnel and students. It is essential to recreate the situation based on the democratic recovery of the nation, that is why the research recognize and remember the Venezuelan university's achievements and success during the first decades of the democracy that began in 1958. University grew vertiginously in number, quality, diversification and presence in the national geography. In those years, there was a generous national budget, produced by the increasing oil incomes, which allowed thousands of families that have never had access to university to celebrate their children's graduation. In this context, university was the best way to get a social ascent, and it was a source of professional people for a society that was in a fast transition from the rural to the urban, and for the ascending "industrialization of import substitution". All these events happened with university autonomy and freedom of teaching, even in the moments of guerrilla confrontation, inspired and supported by the Cuban regimen. This article aims that it is not possible to reconstruct Venezuelan university with the previous models, because the government is in debt and in state of ruin, and the productive company in agony. The rebirth requires a strong, effective and productive alliance between companies and university, with the diversification of financial sources and the reestablishment of autonomy and freedom of teaching. Here are some indispensable conditions for the Venezuelan university's rebirth.
\end{abstract}

Key words

University ruins, Venezuelan ruins, Democratic change, Rebirth, Autonomy.

\section{Desafios para a universidade 2020 na Venezuela}

\section{Sumário}

O presente artigo aborda a dramática situação atual da Universidade Venezuelana, com a extrema perda de orçamento, professores, pesquisadores, funcionários e estudantes; é essencial recriá-la, junto com a recuperação democrática da nação. As conquistas e sucessos da Universidade Venezuelana são reconhecidos e lembrados nas primeiras décadas da democracia de 1958, onde a Universidade cresceu vertiginosamente em número, qualidade, diversificação, e presença na geografia nacional. Naqueles anos houve um generoso financiamento nacional, graças ao aumento da renda do petróleo, que permitiu que centenas de milhares de famílias, que nunca chegaram à universidade, celebrassem a formatura de suas filhas e filhos. A Universidade foi o melhor meio de ascensão social e fonte de profissionais para uma sociedade que rapidamente mudou do meio rural ao urbano, e para a crescente "industria da substituição de importações”. Tudo isso com autonomia universitária e liberdade acadêmica, mesmo na 
época do confronto da guerrilha, inspirada e apoiada pelo regime cubano. O artigo observa que não é possível reconstruir a Universidade Venezuelana nos esquemas e modelos anteriores porque o Estado está endividado, arruinado e com sua produtora em agonia. O renascimento requer uma parceria forte, eficaz e produtiva entre a empresa e a Universidade, com diversificação de fontes de financiamento, restauração da autonomia e da liberdade acadêmica. Algumas condições indispensáveis para o renascimento da Universidade são mencionadas aqui.

\section{Palavras-chave}

Ruína do país e da Universidade. Mudança democrática, renascimento e autonomia.

\section{Nota previa}

En estos últimos 20 años, mientras el país estaba entretenido en otros debates, la revolución informática avanzó tanto en el mundo que no es posible abordar el futuro de la universidad sin un análisis de las nuevas posibilidades y grandes modificaciones que trae para el desarrollo del conocimiento en el país, y el modo en el que se reconfigura el sistema universitario. Al ver la lista de colaboradores en este número de la revista, aprecio con agrado nombres de personas que seguramente abordarán este imprescindible aspecto de la revolución informática con conocimiento y competencias de las que yo carezco.

La tragedia nacional venezolana nos obliga a repensar todo de nuevo; el sistema educativo y la universidad no son una excepción. Nada de lo que tuvimos durante las décadas anteriores es viable a futuro; tampoco la universidad. Es indispensable hacernos con frescura y novedad crítica la pregunta qué universidad queremos y podemos para qué país. No basta querer, sino que hay que ver las condiciones de posibilidad y el modo de llevarlo a la práctica. Si antes de alguna manera podíamos evadir esta pregunta crítica, ahora no hay posibilidad de liberarnos, porque hoy en Venezuela no subsiste la universidad que durante medio siglo hizo tantos aportes al país, y la nueva universidad no ha nacido todavía y no sabernos cómo y bajo qué condiciones puede nacer.

Cómo hacer posible a partir del 2020 el resurgimiento de la universidad que hoy está en ruinas. Con qué presupuesto y fuentes de financiamiento. Cuál ha de ser su compromiso y aportes precisos a la reconstrucción del país. Cómo hacer que en la actual globalización las universidades venezolanas no se conviertan en solo "extractivistas" de los mejores talentos -financiados y preparados por su país y sin compromisos ni obligaciones con él-para brindarlos a las corporaciones transnacionales, cuyas factorías productivas ya no modelan nuestro país, sino que, por mucho, mantienen algunos enclaves sin generar transformaciones sociopolíticas significativas, ni una economía que fortalezca las capacidades del país. Con la globalización de los capitales y la revolución informática, la presencia física de las grandes fábricas respaldadas por inmensas barriadas proletarias ha ido desapareciendo. Hoy, en la economía globalizada, el espacio geográfico de su ubicación es un factor menos determinante y más flexible a la combinación espacial de los factores de producción. 


\section{Logros democráticos universitarios}

La universidad venezolana apenas tenía unos centenares de estudiantes concentrados en Caracas y en un par de ciudades más cuando, en 1928, los futuros padres de la democracia venezolana, desde su condición de estudiantes universitarios, irrumpieron en la política nacional demostrándole al dictador Juan Vicente Gómez que la semana del estudiante y los festejos de carnaval podían debilitarlo más que la tradicional carga a machete de montoneras campesinas tras su caudillo, y que una reina de fiesta y un par de estudiantes elocuentes tenían aún más alcance para sacudir conciencias y cuestionar su poder. En la universidad de hace 90 años (1928) estaba el nuevo epicentro del futuro nacional.

Treinta años más tarde, en la huida del dictador y el amanecer democrático del 23 de enero de 1958, la universidad sería clave, aunque las 6 instituciones de educación superior, incluido el Pedagógico, no sumaban 10 mil estudiantes. Medio siglo después, el número de universitarios inscritos pasaba de $2 \mathrm{mi}-$ llones $300 \mathrm{mil}$, aunque el número de los estudiantes efectivos fuera muy inferior al de inscritos.

Ahora en el 2019 el ausentismo universitario, la deserción y el éxodo del país afectan a más de la mitad de la población universitaria, que en algunas áreas y facultades asciende al 70\%.

En el período democrático, a partir de 1958, hay logros importantes que conviene recordar:

En las dos primeras décadas, de 1958 a 1978, la universidad venezolana y los institutos de educación superior se diversificaron tanto en su ubicación geográfica como en la variedad de sus instituciones: autónomas y experimentales, con investigación o solo formación de profesionales, de financiamiento privado y oficial, de carreras largas y cortas... La diversificación geográfica llevó la universidad al Oriente y Sur del país - que habían estado más abandonadosy de la concentración en las cuatro o cinco grandes ciudades alcanzó con centros universitarios decenas de centros urbanos de regular magnitud.

En esas dos primeras décadas, la universidad venezolana fue una de las principales vías de ascenso social y nutrió las bases para el cambio. La universidad -sobre todo, la financiada íntegramente por el presupuesto público, la llamada "gratuita"- hizo posible que numerosas familias celebraran por primera vez la graduación universitaria de un hijo o una hija. 
Paralelamente, desde el gobierno se abrieron puertas amplias para realizar estudios de postgrado en el extranjero, financiados por el Estado venezolano y con grandes posibilidades también para los opositores al gobierno. En la década de los sesenta, el enfrentamiento político de la izquierda marxista y su lucha armada (animada por el ejemplo y el apoyo de Cuba) contra la "democracia burguesa", tuvieron como epicentro la universidad: durante más de una década predominaron los grupos marxistas en las elecciones universitarias, teniendo un verdadero acceso a los cargos y puestos de poder. En muchos sentidos las autoridades universitarias se mantuvieron enfrentadas a los gobiernos que financiaban la universidad. A pesar de enfrentamientos e incidentes se mantuvo la autonomía universitaria y las universidades se fortalecieron y se expandieron.

El fuerte incremento del número de universitarios no fue exclusivamente venezolano, sino que se dio en toda América Latina, donde los 267 mil estudiantes universitarios que había en 1950, aumentaron a 7 millones en 1990, y a 23 millones en 2012. Sin duda este número continuó en aumento los años siguientes. Avances cuantitativos importantes nos llevan a preguntas obligadas: cómo evoluciona su calidad, cómo responden los egresados a las necesidades de la sociedad; muy específicamente, cómo se relaciona este crecimiento numérico con la brecha existente entre la universidad y los sectores más pobres de la sociedad, y cómo contribuyen sus egresados a la superación de la pobreza. Las urgentes preguntas que nos hacíamos en 2013 sobre calidad, autonomía y pluralismo democrático, ahora se vuelven dramáticas y surge la urgencia de repensar la universidad como la palanca fundamental de una democracia social poseedora de dinámicas productivas que vuelven sostenible e inclusivo el progreso en la sociedad.

En el año 1991, en un cuadro internacional comparativo, el problema universitario de Venezuela parecía más cualitativo que cuantitativo, pues el porcentaje de estudiantes en educación superior, sobre el total de la población, superaba al de la mayoría de los países europeos, Israel y Japón. Posteriormente, entre 1992 y 2005, se duplicó el total de estudiantes de carreras largas (5 años) y cortas (3 años en institutos y colegios universitarios). Al mismo tiempo se aceleró la diversificación de los estudios de educación superior. En el año 2004 había 48 universidades (23 oficiales y 25 privadas) y 119 institutos universitarios (51 oficiales y 68 privados) para un total de 167 instituciones de educación superior: 74 oficiales y 93 privadas. (Fuente: Departamento de Estadística CNU- OPSU). Ese año, el total de estudiantes de nivel superior era de 1,123,063; 614,341 estaba en las oficiales y 508,722 en las privadas, distribuidos de la siguiente manera: dos de cada tres estudiaban en las universidades de financiamiento oficial $(473,587)$, y uno en las privadas $(207,478)$; mientras que en los institutos universitarios la proporción era 
inversa, 140,754 estaba en las oficiales y 301,244 en las privadas. En los primeros 5 años del gobierno chavista (1999-2004) se duplicó el número de estudiantes en la educación superior privada.

Finalmente, resaltamos como dato significativo que en el año 2004, por primera vez en la historia del país, egresaron más graduados de la educación superior privada $(53,056)$ que de los centros oficiales $(48,228)$. El hecho de tener más graduados, siendo menor el número de estudiantes, refleja el alto índice de retirados y repetidores de las instituciones oficiales.

Tanto en las universidades oficiales como en las privadas, había instituciones de buena calidad y otras que dejaban mucho que desear. Pocos años más tarde -tal vez como una manera de incrementar el número de universitarios- unificaron el sistema de educación superior con la suma de institutos y universidades, lo que pronto reflejaría que el número de inscritos universitarios había superado los dos millones.

\section{Cambios, retrocesos y dificultades}

En el año 2013 moría Hugo Chávez en Cuba luego de 15 años en el poder, el tiempo equivalente a tres períodos presidenciales democráticos, que, vistos desde el poder, se consideraban muy cortos para el deseado cambio "revolucionario" del sistema económico, político y social. Junto con el régimen cubano, se acordó que Maduro fuera el sucesor para garantizar la perpetuación del "socialismo del siglo XXI". Hoy el régimen tiene 20 años en el poder, y Maduro trata de agregar, sin legítima elección democrática, otro período presidencial de 6 años.

En el año 2013 escribimos, sin publicar, la reflexión acerca de ciertas realidades y tendencias de la universidad venezolana. Nos parece interesante recogerlas hoy y ver lo que se ha confirmado, cuáles son, actualmente, los cambios necesarios para la sociedad, la política y la universidad.

\section{Diversificación de la educación superior}

Hace ya 30 años que la educación superior venezolana está muy diversificada según el tipo de institución y la variedad de los estudios, que pueden dividirse en: carreras cortas, largas, de investigación, acento exclusivo para la formación de profesionales.

Al margen del presupuesto estatal, las universidades privadas han crecido mucho y han desempeñado una importante función pública, donde sus rectores entregan el título "en nombre de la República y por autoridad de la ley", rectores de universidades privadas debidamente reconocidos e investidos de la autoridad pública de entregar títulos en nombre de la República.

En las últimas décadas se han multiplicado las oportunidades de realizar estudios de postgrado, desde especializaciones en áreas muy específicas, hasta doctorados. También se ha impulsado la tendencia internacional de reducir las carreras básicas de cinco a cuatro años, o incluso a tres, lo que permite entrar al mundo laboral de forma veloz, y, posteriormente, combinando el trabajo con el estudio, continuar la formación a lo largo de la vida, con estudios presenciales o a distancia, en universidades naciona- 
les o extranjeras -aun sin ausentarse del país-, haciendo uso del acceso a la inmensa oferta electrónica. Esto hace que, dejando de lado los primeros semestres universitarios, el resto de los estudios dependa de las decisiones y las elecciones personales no cubiertas por el financiamiento público obligatorio. En la mayoría de los casos se trata de una inversión que realiza cada persona - con eventual apoyo de su familia y empresa- asumiendo los costos y valiéndose de los diversos mecanismos de financiamiento disponibles.

Desde hace varias décadas, y en contra de la gratuidad proclamada en la ley, fueron tomando cuerpo tres tendencias de fondo. La gratuidad se volvía contradictoria e insostenible, la universidad autónoma era cada vez más dependiente y muchos de los jóvenes de las escuelas más pobres eran excluidos de la universidad "popular y gratuita". Esta exclusión no fue por prohibiciones o exigencias de pago, sino debido a la deficiente formación académica que les impedía iniciar y proseguir exitosamente sus estudios universitarios.

\section{Clase media y universidad "gratuita"}

Entre 1958 y 1978 la universidad potenció el ascenso de sus egresados y respondió al tránsito acelerado de la sociedad rural a la urbana. Fue surgiendo así una "clase media" profesional empleada por la burocracia estatal, por las nuevas empresas que nacieron con la política industrial de sustitución de importaciones, y por la urbanización acelerada que requirió construcción, infraestructura y servicios públicos y privados. Se ampliaron las oportunidades de empleo para los profesionales venezolanos e incluso para los llegados de otros países. Así creció rápidamente la "clase media”, con fronteras difusas, una población en ascenso, crecientes aspiraciones y recursos disponibles. Esta realidad social rápidamente en el sistema educativo con el crecimiento de la educación privada, pagada con los recursos de la propia familia. Este fenómeno ocurre en todos los niveles educativos.

A medida que se va ampliando la prosecución escolar y crecen los liceos públicos y privados, muchos profesionales universitarios, que estudiaron en liceos públicos, ahora envían a sus hijos e hijas a colegios privados buscando calidad y, tal vez, diferenciación social. En las décadas anteriores se consideraba que los liceos eran de mejor calidad que los colegios privados, pero esto ha ido cambiando y muchos profesionales envían a sus hijos a colegios privados, mientras que los liceos van quedando para los sectores con menos recursos. De ahí se deriva el hecho de que en el examen de ingreso a la universidad, y la consiguiente asignación de cupos, cada vez prevalecen más quienes provienen de colegios privados, aunque estos representen aproximadamente la cuarta parte de la educación secundaria. Crecen las instituciones universitarias privadas y quienes no pueden entrar en las universidades buscan institutos universitarios (la mayoría privados) carreras cortas, a veces de baja calidad. De esta manera va surgiendo una paradoja: numerosas familias cuyos hijos estudiaron en los liceos financiados por el Estado quedan excluidas de la universidad "gratuita" en los exámenes de ingreso y se ven obligados a estudiar en institutos privados de pago. Esta realidad, unida a la rígida defensa de una universidad 
íntegramente financiada por el Estado, lleva a que las carreras más prestigiosas y buscadas como derecho, medicina o ingeniería, en la universidad "gratuita" sea preferentemente para las familias con más recursos, cuyos hijos estudiaron en colegios privados, mientras que muchos otros, que estudiaron en liceos oficiales, se ven obligados a pagar estudios superiores en instituciones privadas. Paradoja que resulta insostenible.

Así, la universidad que, en las dos primeras décadas de la democracia fue una excelente oportunidad para los sectores de menores ingresos y jóvenes con talento y voluntad de estudios superiores, en las décadas finales del siglo XX se convirtió en el espacio preferente para la "clase media", y algunos "revolucionarios" llegaron a la conclusión de que es inaceptable el examen de admisión que se utilizaba y que en la práctica excluía a los más pobres, provenientes de la educación más pobre. Incluso se argumenta que el examen de ingreso a la universidad se opone o restringe al derecho constitucional de realizar estudios universitarios. Ante esta realidad, el Gobierno "revolucionario" (o sectores del mismo) propuso eliminar los exámenes de admisión universitaria y abrió nuevas universidades paralelas con autoridades nombradas por el Ejecutivo, políticamente leales y dispuestas a admitir a los cientos de miles de jóvenes que difícilmente podrían entrar en las otras universidades con los mecanismos de admisión establecidos. Así, la UNEFA (Universidad de la Fuerza Armada), la Universidad Bolivariana, y la Misión Sucre (que complementa en los estudios del tercer nivel la Misión Rivas, creada para que jóvenes que no pudieron culminar sus estudios de bachillerato pudieran hacerlo a través de programas acelerados especiales).

Estas tres universidades, en poco tiempo, llegaron a sumar más de medio millón de estudiantes bajo la misión "revolucionaria" de abrir las puertas de la educación 
superior a los excluidos y garantizarles una formación "socialista". Para ello recibirían un trato preferencial del gobierno, esperando que sus estudiantes retribuyeran con lealtad política. Crece vertiginosamente el número de inscritos en ellas, y la calidad pasa a segundo plano ante la lealtad política. En el conjunto de la universidad "gratuita" el presupuesto oficial por alumno decrece, pues cantidades similares deben distribuirse entre más alumnos e instituciones, con lo cual se precipita el empobrecimiento de las universidades autónomas y se deteriora gravemente la capacidad de retener a los mejores talentos, como son los investigadores y los profesores cualificados. Este hecho, combinado con el errado principio de que las universidades reciben por igual su presupuesto de acuerdo al número de estudiantes, lleva a la conclusión de que deberían destinarse 30 veces más recursos a la Universidad Bolivariana que a la Simón Bolívar, por ejemplo. El corolario de esta lógica -perversa, pero con cierta apariencia de justicia igualitaria- es que ahora (pensábamos hace una década) los "burgueses" de la universidad Simón Bolívar tienen el presupuesto y los laboratorios que por justicia corresponden a los "pobres" de la Bolivariana. Este razonamiento olvida la diversificación de la calidad universitaria, los diferentes costos de las carreras, los altos costos de la investigación, que haya menos estudiantes, etc., y busca una nivelación hacia abajo, que es la ruina de la universidad. Ruina que ya hemos alcanzado en 2019, con universidades exigentes como la Simón Bolívar o la UCv, casi desmanteladas por falta de autonomía en el financiamiento y por su no subordinación al régimen "revolucionario".

Los sueldos universitarios de la década de los sesenta se habían reducido en términos reales a la tercera parte, las expectativas profesionales en otras áreas del país, o fuera de nuestras fronteras, drenaban de manera peligrosa la calidad de la universidad. Esta tendencia que señalábamos en 2013 como peligrosa, ahora se impone con la hiperinflación de 20182019, que derrumbó las oportunidades de trabajo en el país y el sueldo (salario mínimo menor a \$10.00 mensuales) se volvió inaceptable e invivible, con lo cual la universidad se vacía hacia el trágico éxodo.

\section{Control de autoridades y de presupuesto}

Sin cierta autonomía presupuestaria, sin autonomía para la elección de las autoridades y con la clara determinación del gobierno-partido de apoderarse de la universidad para formar "revolucionarios", parecía decidida la muerte de la universidad autónoma, aunque estuviera consagrada en la nueva Constitución (artículo 109). La tendencia del gobierno "revolucionario" era lógica: hacer que todas las universidades financiadas por él fueran formadoras de socialistas. Para ello tenía el control de los presupuestos y necesitaba lograr imponer las autoridades; en primer lugar "de facto", sin esperar a la nueva Ley de Universidades, que fue elaborada hace una década, que trataron de imponer y fue vetada por Chávez al ver la inviabilidad de la misma y del sistema electoral que proponía. Todavía en 2019 esta nueva Ley de Educación Superior no había sido aprobada y, desde hace casi una década, siguen bloqueadas por el régimen las elecciones en las universidades autónomas, y congeladas sus autoridades electas, 
con períodos de gobierno vencidos hace muchos años. También el CNU (Consejo Nacional de Universidades), diseñado como lugar de encuentro, de discusión y decisiones participadas de la política universitaria, perdió ese significado democrático y fue sustituido por una política más impositiva por parte del Ejecutivo. Anteriormente el CNU era un lugar de encuentro presidido por un ministro y con participación de todos los rectores, representantes de profesores, estudiantes y con representantes del poder Legislativo. Hoy en día se ha desvirtuado en la práctica y el Ejecutivo impone su política. Recientemente, el 27 de agosto de 2019, por medio de una sentencia anticonstitucional de la Sala Constitucional del Tribunal Supremo de Justicia, se impuso una fórmula electoral de las autoridades con voto universal e igualitario de empleados, obreros, docentes, egresados y estudiantes. Como la fórmula no es viable, y es muy improbable que sea acatada por la comunidad universitaria, la sentencia adelanta que el Ejecutivo, luego de seis meses, "designará a las autoridades que le parezcan sin participación alguna de la comunidad universitaria". No es una fórmula viable, sino la vía para apoderarse de las universidades autónomas que, en veinte años, no han logrado ganar las elecciones de sus autoridades. De esa manera, en todas las universidades de financiamiento oficial (no en las privadas) el Ejecutivo nombraría las autoridades, como es y ha sido en Cuba y en otros regímenes similares.

En cuanto al financiamiento, el régimen buscaba ahogar o arrodillar a las grandes universidades democráticas y autónomas (totalmente dependientes del presupuesto nacional). Ahora en 2019, se ha consumado el desastre que preveíamos en 2013. Con la hiperinflación $(1,700,000 \%$ anual) desatada en 2018, este año el presupuesto asignado por el gobierno a las universidades autónomas no llegó a cubrir el 10\% de las necesidades y los salarios del personal académico, aun los más elevados están por debajo de $\$ 20$ o \$30 al mes.

Por otra parte, hay varios hechos financieros innegables que a veces se olvidan en esta pugna por el control político de la universidad. El financiamiento de los estudios universitarios o de educación superior tiene en Venezuela tres características que resultan negativas:

a.- No toma en cuenta ni estimula las diversas formas de contribución financiera de la sociedad en las universidades, además del presupuesto oficial universitario.

b.- No ha resuelto la duplicación de la nómina al incluir en el presupuesto de cada año a los jubilados, además del personal activo. Con los años crece el número de jubilados que se suman a los activos a la hora de pagar la nómina, con la consecuencia de reducción de ingresos para estos.

c.- No ha frenado el alarmante empobrecimiento de la Universidad y su creciente incapacidad para retener los mejores talentos, a quienes la sociedad ofrece alternativas más atractivas de trabajo e ingreso dentro o fuera del país (más fuera que dentro). Hoy la trágica realidad presupuestaria desborda toda racionalidad.

El análisis detenido de cada punto desborda los límites de este artículo. 


\section{Democracia, autonomía universitaria y elecciones}

Para un régimen que se considera "revolucionario", con ideología marxista y defensor de modelos políticos estatistas al estilo soviético y cubano, solo es tolerable la existencia de universidades autónomas del poder del estado-partido-gobierno como un período de transición. En la Cuba actual, o en la Alemania Oriental del pasado, es inconcebible la existencia de universidades financiadas por el Estado con autonomía y pluralismo en relación al gobierno. Las autoridades universitarias deben ser nombradas por el gobierno "revolucionario" y seguir fielmente la línea política de éste para la implantación de una visión exclusiva y única de la vida y la sociedad con el "socialismo del siglo XXI". Quien no lo haga es simplemente traidor a la revolución. No es aceptable -dicen- que un gobierno revolucionario financie una educación capitalista y que en las elecciones de autoridades y representantes universitarios prevalezcan los no "revolucionarios", o los opuestos al socialismo estatista. Es necesario cambiar el modo de elección de las autoridades. El ideal sería que éstas fueran nombradas por el Ejecutivo sin elección alguna, como se hace en todas las universidades "experimentales" cuyas autoridades nombra el Ejecutivo.

Hay tres puntos de asedio para cercar y apoderarse de la universidad autónoma: el sistema de admisión, el sistema de escogencia de autoridades y representantes, y el cerco financiero, que lleva al empobrecimiento e incapacidad de la universidad para retener personal académico y administrativo de alto nivel. El Ejecutivo actual tiene todo el poder para hacer las leyes que necesite para ello, solo la resistencia universitaria y de la sociedad democrática podrá impedirlo. La autonomía universitaria, que incluso está reconocida rotundamente en la actual Constitución (art. 109), es un principio basado en la naturaleza misma de la universidad y del trabajo intelectual con libertad de pensamiento, de cátedra y de investigación, y con la autonomía administrativa correspondiente. En una sociedad democrática, el pluralismo de pensamiento es inseparable de la autonomía universitaria y un principio válido para todas las universidades, sean "autónomas", "experimentales" o "privadas". Todas ellas forman un sistema universitario único, que es un público con iniciativas y formas de gestión diversas, consagradas en sus respectivos estatutos oficialmente reconocidos.

\section{Provisionalidad de las universidades privadas}

Por su parte, las universidades privadas tampoco tienen sentido en este modelo sociopolítico, y su mera existencia se considera contradictoria con la ideología del régimen. Debido a esto tienen una existencia provisional tolerada y se busca su extinción por ahogamiento, aunque no por decreto dictatorial, que sería más escandaloso y movilizaría resistencias. Ya que, de acuerdo al régimen, estarían viviendo un período de transición con un régimen que trabaja por la implantación de la universidad socialista y por la extinción de las otras formas de universidad todavía existentes. 
Las universidades privadas han sido cercadas de dos maneras: por la negación en los últimos 15 años de toda solicitud de fundar nuevas universidades, abrir carreras nuevas, realizar ampliaciones y modificaciones sustanciales en los estudios de pre y de postgrado; y también por obstaculizar toda proyección de estas universidades en otros niveles educativos, como labores de refuerzo escolar en las escuelas secundarias, apoyo a la formación permanente de los docentes, o negación sistemática de empleo en la educación oficial al personal educativo salido de las privadas o de las autónomas, salvo que fueran militantes del partido oficial. La otra forma de estrangular la educación privada es impidiendo (en tiempos de hiperinflación) que se mantengan los valores reales de las mensualidades que se cobran para asegurar la calidad con un profesorado bien pagado y las inversiones necesarias en el mantenimiento y desarrollo de la planta universitaria. En 2013-2014 decíamos que en la educación básica y secundaria el Ministerio sólo permitía aumentos en las mensualidades muy por debajo de la inflación (entonces $10 \%$ de aumento frente al 45\% de inflación). Con esta brecha sostenida durante varios años se caminaba al cierre, pues el obligado déficit acentuaba y agravaba el deterioro de la inversión educativa en el personal y la dotación de los centros educativos privados. En el nivel universitario hay cierta autonomía legal de que cada universidad elabore sus presupuestos con los aumentos necesarios de ingresos y egresos, pero aun así son fuertes la presión y el hostigamiento oficial en algunas universidades. Este peligro se volvió una realidad catastrófica en 2018, cuando la hiperinflación fue cercana a $2,000,000 \%$ anual y barrió con toda posibilidad económica. Esta realidad obligaría por lo menos a indexar o dolarizar los salarios y los demás capítulos del gasto y de la inversión universitaria, y para ello tendrían que indexar las mensualidades que cobran, lo que es absolutamente imposible por el brutal empobrecimiento de los salarios y el ingreso de las familias que tienen que pagar. Una situación insoluble mientras dure la hiperinflación, que alimenta la trágica tendencia a abandonar el país tanto de los profesores universitarios como de los estudiantes y sus familias. La Universidad privada sobrevive con grandes esfuerzos, pero esto no es lamentado por un gobierno cuya ideología exige la eliminación de la educación privada en todos los niveles, como en Cuba.

\section{Qué universidad para qué sociedad}

Ante la destrucción de la universidad y la total imposibilidad de restablecerla como era, es necesario preguntarnos de nuevo qué universidad queremos, para qué sociedad, y qué universidad somos capaces de crear y sustentar con la empobrecida sociedad que tenemos y vamos a seguir teniendo los próximos años. Debemos reflexionar sobre el significado y el papel estratégico y concreto de la universidad venezolana en la reconstrucción del destrozado país. Si queremos una sociedad democrática e inclusiva, es necesario preguntarnos qué significa hoy y mañana la universidad venezolana para el desarrollo del país, para la esperanza de los pobres y su futuro como ciudadanos dignos. No basta decir lo que fue en las primeras décadas de la democracia, sino reconocer que hoy la realidad es otra y que está muy alterada la relación entre sociedad, universidad y política. La condición de 
las posibilidades de una universidad democrática renovada exige renunciar a principios que nos parecían irrenunciables para reconstruir con gran esfuerzo y de acuerdo a las nuevas realidades. Para ello conviene reforzar algunos principios y criterios.

El sistema universitario venezolano, como casi el de todos los países del mundo, es de gestión y financiamiento mixto, e incluye universidades tanto de iniciativa y financiamiento oficial como privado. La función pública es común en ambas. Las "privadas", por su presencia cuantitativa y cualitativa, no son una realidad marginal ni excepcional.

\section{Nadie debe ser excluido por falta de recursos}

Venezuela necesita que todos sus jóvenes tengan las bases educativas adecuadas para poder seguir sus estudios en el nivel superior y, al mismo tiempo, exista el respaldo financiero necesario para ello. Es fundamental defender el principio básico de que nadie quede excluido de los estudios universitarios por falta de recursos económicos familiares, ni debido a que su formación básica careció de la preparación necesaria para ingresar al nivel superior. Para asegurar que ningún joven con aptitudes y actitudes quede excluido de la universidad por falta de recursos, el financiamiento oficial debe dar prioridad a los sectores con menos recursos que reúnan las demás cualidades. Lamentablemente, en Venezuela los recursos del presupuesto público no son, y no van a ser, suficientes para brindar a todos una universidad "gratuita". Por otro lado, el país necesita más jóvenes egresados de escuelas técnicas y preparados para oficios que no requieran de un título universitario.

\section{Equidad de ingreso y egreso para la equidad}

La universidad venezolana reconstruida necesitará recuperar un número razonable de estudiantes, pero sus estudios no podrán ser íntegramente absorbidos por el empobrecido presupuesto público. El presupuesto educativo oficial tiene enormes responsabilidades en los niveles de educación maternal, preescolar, primaria y secundaria para tratar de lograr que el $100 \%$ de los niños y jóvenes esté en la escuela con una educación obligatoria y de calidad. Sin educación de calidad en todos en esos niveles, seguiremos perpetuando, reforzando, e incluso sembrando la pobreza y la discriminación social. La buena calidad de la educación superior tiene valor estratégico para el país y el Estado tiene gran responsabilidad sobre ella, pero no puede ser la única fuente de ingreso para el pago de las mensualidades, por lo que es necesario promover otras fuentes, y asegurar que los más pobres tengan la prioridad en el financiamiento estatal.

Para no incurrir en engaños, frustraciones y fracasos de miles de jóvenes en su primer semestre universitario, es impres- 
cindible que se ingrese a cada carrera con los requisitos y bases necesarias para cursarla. Por ejemplo, no se puede estudiar la carrera de ingeniería sin una buena base en matemáticas. Lamentablemente, en nivel secundaria hay un déficit generalizado de profesores de matemáticas, física, biología, inglés..., y la triste realidad es que en los últimos años ha bajado de forma considerable el nivel de preparación que los jóvenes demuestran en los exámenes de ingreso a la universidad. Por esta razón, y otras, el ingreso a la Universidad no puede ser sin orientación profesional y sin las bases necesarias. Lo contrario lleva al fracaso, a la frustración del estudiante y al despilfarro millonario de los escasos recursos públicos educativos. El modo de abrir aún más las puertas universitarias a sectores con menos recursos es elevando el nivel educativo de sus escuelas y comprometiendo a la universidad en el fortalecimiento y la calidad del sistema educativo en las etapas anteriores, empezando con la educación básica. No es la universidad la que rechaza la entrada de un estudiante, sino la falta de preparación. La universidad debe ser la mejor aliada de los jóvenes desde antes de aspirar a entrar a ella. Está demostrado que las desventajas de los pobres así como la mala calidad de la educación que reciben son las que niegan (con frecuencia están ya excluidos antes de cumplir los diez años) su entrada a la universidad, pues sobre cimientos débiles nada sólido se puede construir. La respuesta está en una universidad comprometida y aliada con el sistema educativo, especialmente con el refuerzo escolar en las escuelas más débiles para contribuir en su nivelación hacia arriba.

Cuando se habla de equidad universitaria se refiere a que en el ingreso a la universidad no deben ser discriminados los más pobres, pero no es menos importante reforzar el aporte de la Universidad a la construcción de un país más equitativo. Que haya equidad a la entrada y que los egresados salgan formados y motivados para la construcción de una sociedad más justa y equitativa. ¿Cultiva la universidad en sus contenidos y prácticas la solidaridad, acerca a los estudiantes y futuros profesionales a la realidad de pobreza y a la de asumir su profesión con compromiso y alianza para superarla? Creemos que en este punto, más allá de las proclamaciones retóricas, las inercias universitarias están llevando a mayores desigualdades. Podremos hablar de equidad universitaria solo si la universidad forma con visión crítica de la sociedad y de su profesión propia, con prácticas sociales bien programadas (más allá de la mera denuncia y protestas), en alianza con los sectores más pobres, con iniciativas para su fortalecimiento y con una visión de un país justo e inclusivo. De lo contrario, la universidad termina siendo un sistema que convierte recursos públicos en títulos privados sin ninguna obligación ni compromiso con el país, y que se puede degenerar en un sistema para detectar los mejores talentos, financiarlos con recursos nacionales y luego facilitar su trasvase hacia empresas transnacionales dentro o fuera del país.

Para que los egresados sean portadores de equidad no basta la motivación y la visión académica de un país solidario y comprometido, sino que es indispensable fortalecer a lo largo de los estudios la práctica del servicio social universitario, así como enfocar sus estudios y pasantías más directamente relacionados con las empresas en el país. 
Para que esto sea verdad, es necesario que la universidad cultive un compromiso de tal vigor y relieve que, idealmente, cada egresado vincule inseparablemente la búsqueda de su éxito personal con el éxito de la sociedad y con la reconstrucción democrática no excluyente de ésta. Hay que desarrollar voluntad y mecanismos para que la ayuda recibida del Estado durante los estudios sea devuelta a la sociedad. Desde hace muchas décadas los graduados de medicina salen con la intención solidaria de pasar un año obligatorio de "rural". Hace 70 años la mayoría del país era rural y muy carente de servicios médicos, y esta es hoy todavía una manera de devolver al país, para su población más pobre y necesitada de médicos, parte de lo recibido en los años de carrera. Solo que ahora la mayoría de los pobres están localizados en los barrios urbanos, por lo que no vemos razones para que no haya políticas similares en todas las demás profesiones. Es necesario cultivar y fomentar en todas las carreras el compromiso y motivación personal para que sus estudios y su profesión redunden en bien del país. Los valores cívicos y la ética sirven de poco sin esa solidaridad ciudadana fundamental.

De manera menos sistemática y decidida, en los años recientes se ha desarrollado en todas las carreras el servicio universitario con pasantías que llevan la universidad a la sociedad y a sus empresas. Consideramos que hay que evaluar esta práctica a lo largo de los años de estudio y reforzarla por su valor como servicio y como medio de formación solidaria. En la urgente reconstrucción del país, es importante recrear puentes entre los diversos sectores sociales que lleven a la solidaridad y al nuevo aliento ético para lograr el reencuentro con la esperanza nacional. 


\section{La imposible "gratuidad" general}

En Venezuela hay una convicción, tal vez predominante, que considera que la universidad debe ser gratuita, es decir, pagada por el presupuesto oficial. Como hemos visto, hace mucho tiempo que esto dejó de ser una realidad, y hace ya 15 años que fue mayor el número de graduados universitarios que realizaron sus estudios sin financiamiento estatal, que los que estudiaron "gratuitamente". Aun en sociedades más ricas que la venezolana no es razonable, ni sostenible, que el Estado financie íntegramente los estudios universitarios de la población. Por eso en Inglaterra, Alemania, USA, Rusia, China, Japón, España, Francia y en otros países desarrollados, los estudios universitarios son financiados en parte por el propio beneficiario y su familia. Asimismo, se desarrollan sistemas de crédito educativo público y privado, y se cuenta con las fundaciones y colaboraciones de las empresas para hacer frente al inmenso gasto e inversión universitaria. Durante varias décadas democráticas la renta petrolera permitió el financiamiento estatal de la "gratuidad" universitaria, incluso parecía criticable el alto porcentaje del presupuesto nacional destinado a la universidad en comparación con el asignado al resto de la educación. En la actual búsqueda venezolana sería iluso, y fuera de toda posibilidad, la idea heredada de que toda la población tiene derecho a que el Estado le financie sus estudios superiores, incluyendo cinco años de licenciatura y ulteriores estudios de postgrado. La universidad renacerá con vigor si se incrementan, explicitan y combinan diversas fuentes de financiamiento como:

1) El presupuesto oficial para las áreas prioritarias de investigación y para facilitar a la población de menos recursos el ingreso y el estudio de los primeros semestres. Apoyar el sistema crediticio y el financiamiento parcial de los estudios, la inversión en dotación actualizada y el mantenimiento de las universidades del Estado.

2) Recursos familiares. En realidad - como mencionamos anteriormente- en América Latina el gran crecimiento del número de universitarios se debe más al incremento del presupuesto de las familias que al aumento del presupuesto estatal.

3) El crédito educativo estatal, con un sistema público administrado privadamente, asegura la transparencia y la recuperación de los préstamos. Un sistema con capacidad de atender a un gran número de estudiantes debe recuperar el capital sin intereses (en términos reales, sin la actual deformación hiperinflacionaria). Que sea pagable a posteriori con un porcentaje razonable del salario del graduado ya empleado.

4) La empresa productiva con una ley (reactivación actualizada de la Lості, Ley Orgánica de Ciencia y Tecnología) que co- 
financie proyectos de interés para las empresas y los realizados en relación más directa entre la universidad y la empresa. Así se contribuye a la dotación, formación, pasantías, etc., en las áreas de especial interés de la industria y del país.

5) Fundaciones nacionales e internacionales de apoyo a la investigación y formación universitaria con convenios e intercambios internacionales.

El desarrollo de diversas fuentes de financiamiento permitirá garantizar que los jóvenes con menores ingresos familiares puedan estudiar los primeros semestres financiados por el Estado y que más tarde, en los dos últimos semestres, puedan acceder a un crédito con obligación de reembolso sin intereses; devolución diferida que solidariamente refuerza el sistema crediticio. El crédito educativo público y privado ha de estar abierto también a los estudios de postgrado. Se requiere un sistema riguroso de cobro, y sugerimos que el financiamiento público se administre en convenio con la banca privada para que la tasa de recuperación sea alta y con administración transparente.

Las familias con recursos contribuirán con parte del pago universitario, como ocurre incluso en los países más desarrollados. A los estudiantes de los últimos semestres y de postgrado les interesa invertir en su formación continua, que podrán pagar con parte de sus ingresos presentes o futuros. Formación continua que, con las actuales oportunidades nacionales o internacionales, presenciales o a distancia, será algo necesario y cada vez más asequible.

Afortunadamente, en los últimos años se ha desarrollado el aporte no estatal para el pago de la educación superior: antes de la actual catástrofe, cerca del $30 \%$ de todo el alumnado y aproximadamente la mitad de los que se graduaban lo hacían en universidades privadas, sin aportes del presupuesto público. En los últimos años, a pesar de ciertas protestas, se ha aceptado que también en las universidades autónomas los beneficiarios paguen sus estudios de postgrado (o un buen porcentaje). Por otra parte, la mayoría de las carreras universitarias básicas se han reducido de 5 a 4 años, e incluso a 3. Posteriormente, una vez iniciado el trabajo profesional, muchos realizan estudios de especialización de acuerdo a intereses específicos de su trabajo y su combinación con estos.

De esta manera el presupuesto público podrá garantizar el pago de los estudios, no de toda la población universitaria, sino para la población de menos recursos: los primeros semestres y las prioridades estratégicas nacionales.

En la crisis actual una de las grandes debilidades de las universidades de financiamiento público es su casi total dependencia del Ejecutivo; realidad que en estos años de "revolución" se ha agravado, pues el poder Legislativo y su aprobación de los presupuestos nacionales han sido anulados, dejando la puerta 
abierta a la imposición del Ejecutivo y su partido. Hablar de autonomía universitaria con total dependencia presupuestaria es algo ficticio. Por ello es importante la diversificación financiera que proponemos, y también la exigente promoción y administración de otros recursos de la propia universidad.

\section{Alianza universidad-empresa}

En el actual desastre nacional ha quedado en evidencia la imposibilidad de lograr un país próspero mientras dure la presente ruina del aparato productivo. Además de otros errores, el más grave es haber llevado al extremo la falsa creencia de que Venezuela es un país riquísimo y que podemos vivir del reparto de la renta petrolera sin necesidad de ser productores exitosos. El hecho es que, con ese enfoque, en los últimos cinco años el descenso acumulado del PIB ha superado el $60 \%$, lo que es muy grave, y se calcula que este año 2019 superará el 35\%. Cambiar esa tendencia exige una nueva alianza entre universidad y empresa en la que esta sea la clave para la transformación productiva del país.

La deformación cultural rentista venía marcando a Venezuela desde el estallido de los primeros pozos petroleros en 1916, que la convirtieron pronto en la primera exportadora del mundo. Esta irrupción petrolera en un país pobre, subdesarrollado y sin instituciones, marcó la política y la economía de las siguientes décadas, con un Estado distribuidor de la renta petrolera, y con una política clientelar que reforzó la errada idea de que la riqueza nacional son el oro y la plata -en nuestro caso el petróleo- en contra de lo que hace más de dos siglos y medio venía enseñando la ciencia económica. Ciertamente la minería genera un primer salto en los ingresos nacionales, pero es necesario convertir una buena parte en inversión productiva; tanto en capital productivo como en formación humana. Venezuela, en parte, lo hizo, y a lo largo de medio siglo se transformó con un crecimiento sostenido de $6 \%$ anual en promedio y con muy baja inflación. Después de la Segunda Guerra Mundial, durante varias décadas, fue el país del mundo que atrajo más migración en proporción al número de habitantes. Migración que aportó mucho talento humano y espíritu de trabajo. A partir de los años 60 se fue generalizando la educación. Sin embargo, la cultura rentista marco muchas mentalidades y políticas públicas, y fue penetrando la falsa idea de que somos un país riquísimo aunque no produzcamos. Hoy estamos pagando las consecuencias. Es dramático, en estos últimos años "revolucionarios", el descenso de la producción y de la productividad de miles de empresas de investigación universitaria y de registro de patentes en Venezuela.

Ahora hay que sembrar por todos los medios la idea de que nuestra riqueza es el talento de los venezolanos, que crece y se cultiva con educación de calidad en todos los niveles; idea que debe orientar la práctica efectiva. La riqueza surge de la empresa productiva potenciada por el talento humano, y para ello es fundamental la alianza entre la empresa y la universidad. La educación ya no podrá seguir siendo para muchos la escala para acceder a la riqueza (petrolera) que ya existe, sino el medio para desarrollar el talento productor de la riqueza que no existe; esta necesidad marca todo el enfoque 
de los estudios. Para superar la situación en la sociedad del conocimiento, es necesario que la empresa renazca con la conciencia y la práctica de carecer del interés de explotar "la fuerza de trabajo", sino de desarrollar permanentemente "el talento de trabajo“, clave para la producción.

Durante la crisis de la década pasada en países europeos y USA, el desempleo afectó mucho más a los egresados universitarios que a los formados en carreras técnicas más cortas, con oficios profesionales, como ocurre en el sistema dual alemán y en las escuelas profesionales españolas. Lamentablemente, en Venezuela la distorsión heredada de las décadas anteriores ha sido llevada al extremo en los últimos 15 años, entregando títulos universitarios con muy poca formación profesional y sentido productivo. Si queremos que el país salga de la lamentable pobreza productiva actual, y de su muy grave dependencia externa, es imprescindible conectar sistemáticamente la universidad con la empresa y formar profesionales con serio compromiso social y productivo.

Es ya fundamental la alianza entre universidad, empresa y Estado (presente en el gobierno nacional y en los gobiernos regionales) para salir de la actual miseria; ha de ser el sello de la universidad que renace. Universidad y empresa unidas desde el diseño de los estudios, las carreras, y aliadas en las prácticas, investigaciones, pasantías, tesis... Esta alianza traerá cambios en el financiamiento de los estudios y formará la nueva conciencia de miles de jóvenes que creen y confían más en su talento que en la renta petrolera. La otra ala de las universidades debe abrirse con más fuerza y decisión hacia las comunidades con programas de servicio social, bien estructurados y acordados con las propias comunidades según sus necesidades y sus proyectos de transformación.

Este nuevo estilo de educación superior debe buscar alianzas internacionales con países de sólida y exitosa colaboración entre Universidad y Empresa.

Para incrementar la productividad del personal universitario hay que introducir estímulos y reconocimientos diferenciados con los correspondientes mecanismos de evaluación.

Lejos de uniformar las universidades y sus presupuestos hay que reconocer su multiplicidad y diversidad. Hay universidades que deben especializarse en investigaciones más costosas, y en cambio otras son menos costosas y más centradas en formación de profesionales. Por otro lado, es necesario que los estudios de pregrado o licenciatura sean más cortos, con posibilidad de empezar a trabajar pronto para luego seguir complementando los estudios especializados de postgrado. Es muy importante elevar la calidad y la cantidad de las carreras cortas de tres años con posibilidades de seguir más adelante en su formación continua. Esto tiene que diseñarse en una relación más estrecha con las empresas públicas y privadas, evitando el costo de carreras largas para quienes se van a ocupar en oficios que no las requieren. 